\title{
Building the readings scale to teach reading and writing to the student of the first grade
}

\author{
Dawoud. D. Helles, ${ }^{1}$ Mahmoud. M. Alrantesi
}

Faculty of Education -Islamic University of Gaza-Palestine

Received: $23^{\text {th }}$ Aug 2020 Revised: $5^{\text {th }}$ Sept 2020 Accepted: $9^{\text {th }}$ Oct $2020 \quad$ DOI: https://doi.org/10.31559/CCSE2020.1.1.3

Abstract: The study aimed at designing the readiness scale of learning to read and write for first grade students when they entered school, and to reveal the impact of the scale in the development of their abilities and the degree of readiness to learn to read and write. The sample of the study consisted of (64) male and female pupils from the first-grade students in Dar Al Arqam Islamic Model School in Gaza. The questions and its vocabulary were constructed in the light of readiness skills for learning to read and write. The scale consisted of (30) questions divided into (5) skills: (visual discrimination, auditory recall, auditory discrimination, auditory recall, auditory interpretation). It was applied to the research sample, the researchers found that there were statistically significant differences at the mean level $(\alpha=0.05)$ in the average readiness to learn literacy between males and females in favor of females. The researchers recommended the need to hold training courses for teachers of kindergarten to deal with the skills necessary for reading and writing readiness.

Keywords: Readiness; reading and writing.

1 Corresponding author

Dawoud. D. Helles

Islamic University of Gaza-Palestine

E-mail: dhelles@iugaza.edu.ps 
International Journal of Childhood, Counselling, \& Special Education (CCSE), Volume1, Issue: 1 , September: 2020, pp.39-57

\section{Introduction}

The process of reading and writing is one of the greatest achievements of the human being as they are the most important means of communication in the present and in the past, and there may be no activity for elementary grades that does not require reading and writing. Besides, they are two tools of knowledge, culture, social and scientific communication, and through them, the individual satisfies his desires, develops his emotions and enriches his experiences and opinions.

Reading and writing truly raises the individual above the level of daily concern and breaks down barriers between himself and others. If this importance for reading and writing is for everyone, then it is the most important for elementary grades, and its importance does not lie only in that it is a teaching subject. Rather, it is used to teach all academic matters, and to succeed in the process of reading and writing, primary grades students avoid many psychological, emotional and educational disorders, and failure to master them leads to more difficulties as a result of lack of early detection to prevent their consequences. Many scientific studies confirm this importance, such as the Algarf study (1994) in the analysis of errors in recognizing written symbols (1), and the Elsea (2001) study (2) in America entitled:
'Developing students' reading and writing skills through the use of Balanced reading and writing "and the study of Barghout (2002) (3) The effectiveness of a program of proposed activities to develop some skills of reading and writing readiness for children with learning difficulties in the kindergarten stage, and the study of Al-Jumaili (2004) (4) that aimed to find out the difficulties of learning reading and writing for novice students from the point of view of teachers And the educational supervisors, and the study of Nejm study (2006) (5), which aimed to uncover the reasons for the weakness of elementary school students in the Arabic language subject from the teachers 'point of view. This importance is represented in identifying the strengths and weaknesses (current level of performance) and it is the responsibility of the classroom teacher to discover the degree of readiness of his students to teach reading and writing. This discovery helps him in planning the most appropriate activities and predicts what students can get from adequate training, as readiness is a feature present in the individual that does not actually come into existence unless there are factors helping to emerge from practice and training. (Al-Nashif, 2005: 25) (1), and AlTahan's study (1994) (2) to reveal the effect of reading readiness among

Dawoud. D. Helles $\mathcal{E}$ Mahmoud.M. Alrantesi 
International Journal of Childhood, Counselling, \& Special Education (CCSE), Volume1, Issue: 1, September: 2020, pp.39-57

children in Riyadh, which was conducted in Mansoura, Egypt, and the Ba'lousha study (2015) (3) to reveal the effect of al-Qaida alNourania in treating reading weakness. From this standpoint, the researchers formed the idea of building a scale of readiness to teach reading and writing to students of the first grade basic, especially since researchers have touched the need for this scale through their experiences and meeting with teachers of primary grades by virtue of their work as two faculty members, and their supervision of field training students.

Study problem

The problem of the study is due to the researchers 'observation through their work in supervising field training students, the continuous meeting with teachers of primary grades, and standing up to the teachers' and parents 'complaints about the teaching and learning to read and write for the first grade basic students and the presence of a number of them unable to acquire reading and writing skills In a way that enables them, and what is the most appropriate training to enable first-grade students to master teaching and learning to read and write, studies have shown that teaching children in the kindergarten stage is one of the most important stages in which a child learns, and that training in acquiring skills at this stage is the most appropriate, and that students The first grade, basic, differs in their readiness, and that the best way is to work to reveal the capabilities of these children upon entering school and their degree of readiness.

Hence, the researchers formed the idea of building a measure of readiness to teach and learn to read and write for the first-grade pupil basic, and the study problem emerged from the following two questions:

(1) What skills should a student in the first grade basic possess when entering school in preparation for teaching and learning to read and write?

(2) Are there statistically significant differences at a significant level $(\alpha \leq 0.05)$ between the average degrees of readiness in teaching and learning to read and write between males and females?

Study hypothesis

"There are no statistically significant differences at a significant level

$(\alpha \leq 0.05)$ between the average scores of first-grade students' readiness for the basis for teaching and learning to read and write due to the gender variable." 
International Journal of Childhood, Counselling, \& Special Education (CCSE), Volume1, Issue: 1, September: 2020, pp.39-57

Study Justifications

Despite the importance of revealing the readiness for teaching and learning to read and write for a first-grade student upon entering the school, and since first-grade students differ in the degree of their readiness and readiness to teach and learn, that learning does not happen suddenly, and that there are no readiness measures in place in basic schools - within the limits of knowledge Researchers - contribute to uncovering the degree of readiness of first-grade students for teaching and learning to read and write, which contributes to building treatment plans to enrich their capabilities and identify strengths and weaknesses (current performance) to design the most appropriate activities for them.

\section{Study Objective:}

(1) Design and create a scale of readiness for teaching and learning to read and write for first grade students when they enter school.

(2) Exposing the effect of the scale on developing the capabilities of first grade students and their degree of readiness to teaching to read, learning to write.

The importance of studying:

(1) The importance of this study is that it provides a measure of the development of preparedness and readiness to teach reading and writing among first grade students.

(2) This study may benefit primary grades teachers and their supervisors in drawing remedial plans to develop preparedness and readiness for teaching and learning to read and write among first grade students.

(3) This study may be useful in early detection of students who suffer problems that impede their abilities to teach reading and writing.

\section{The boundaries of the study:}

Objective boundaries: The objective boundaries are the design and construction of a measure of readiness to teach and learn to read and write for first-grade students when they enter school.

Spatial boundaries: Dar Al-Arqam Islamic Schools in the Gaza Governorate (East-West)

Time limits: the first semester of the 2019-2020 academic year

Human limits: Basic first-grade students.

\section{Terminology of study:}

(1) readiness to learn: Zaki Muhammad (2002 - 48) (1) defined it as: preparing an individual from the physical and 
International Journal of Childhood, Counselling, \& Special Education (CCSE), Volume1, Issue: 1, September: 2020, pp.39-57

mental standpoint before starting to teach a skill.

- Al-Hefni points out that readiness is: "The inherent ability of an individual with which if his owner was trained, he would be able to do the work on training it." (shogair and Halles 2010, p. 39) (2)

- It was stated in the dictionary of psychology Faraj \&others. (B. T) (3) that the willingness to learn is: "The latent ability or performance expected to be reached by the individual later, on the basis of which it is possible to predict the future ability to do an action or assume responsibility or achievement, and if the individual acquires $\mathrm{A}$ practice or training regarding the preparation of the preparations, the readiness became an ability.

- The two researchers define it procedurally as: "An individual's latent capacity, which is referred to by natural maturity and learning into an ability.

Actual, which is known as an individual's ability to learn.

(2) readiness for teaching and learning to read and write

The process of teaching and learning to read and write takes a long time for the child to be able to, it needs maturity and training and begins before school, And educational scholars call it:
"Preparation to read and write" (Zaki Muhammad, 2002: 49) (1) This is the most important stage for providing children with the skill of reading and writing.

Teaching and learning children to read and write is not linked to the child's reaching the age of six, as some believe, and this contradicts the findings of physiologists and nervous system scientists, as muscle growth for some children may not be completed (Al-Jumaili, 2004) Based on this opinion, chronological age is not the factor. Critical for starting the literacy teaching and learning process

The two researchers define the readiness for teaching and learning to read and write procedurally as: "The inherent ability of the firstgrade pupil to acquire the concepts and skills that develop his readiness for teaching and learning to read and write."

\section{3- Basic first grade:}

The first grade of the basic stage, which starts from (first to tenth), and the ages of students in this grade are (5.8-6) years when they enter school.

The theoretical framework of the study:

Factors of readiness to read and write:

There are factors that contribute to preparing children to teach and learn to read and write, including: 
International Journal of Childhood, Counselling, \& Special Education (CCSE), Volume1, Issue: 1, September: 2020, pp.39-57

1. Mental readiness:

Success in reading and writing requires a certain amount of mental maturity, and there is a correlation between mental age and reading success. (Al-Tahan, 2003: 28) (3). The educational scholars disagreed about the mental age required to be met. For the child to be ready to teach and learn to read and write, some said as Saed and Faiqah (2002) (4), Helles (2019) (5), Snow \& Griffin (1998) (1): The child reaches this age between six and six and a half years old, and another team reported that children reach this age before they reach the age of six, and some of them do not reach this mental level until later and the reason is that maturity The mental is affected by many influences, including: health - psychological educational. Mental age should not be the only measure for children at this stage, and a skilled teacher is one who understands these matters and works to bridge the gap between the different mental levels between children, and works to adapt the educational material according to the maturity of each one of them, thus ensuring the teaching of reading and writing in an enjoyable way that children desire.

2. Physical readiness:

Reading and writing is not only a mental process; Rather the senses of hearing, sight and articulation depend, and general health and safety is one of the reasons for the success of preparation and a factor of academic delay, and a healthy child is the most capable of teaching and learning to read and write. Reading and writing require functional use of both the senses of hearing and sight in addition to speech (Al-Mutlaq, 2004: 121) (2), and the teacher must make sure of the adequacy of physical preparation, as the senses, such as the eyes, hearing, and speech apparatus are all effective factors in forming the ability to read and write.

Among the manifestations of poor physical maturity of some of the senses:

- The child's ability to see things, and his inability to see details of them.

- The child's ability to see some letters and see them upside down, and his inability to differentiate between them, such as: (A , B, C, D, $\mathrm{E}, \ldots)$

- The child's hearing may be sound, but it lacks accuracy in distinguishing between sounds, especially close and similar sounds. The ability to distinguish between sounds is the basis for teaching and learning to read and write.

- The child's ability to remove the letters from their original exits, and speaking clearly contributes to the success of teaching and learning to read and write, and the defect, whether it is accidental or 
International Journal of Childhood, Counselling, \& Special Education (CCSE), Volume1, Issue: 1, September: 2020, pp.39-57

physiological, requires the teacher to know it. Correction is easy by searching for reasons.

\section{Emotional readiness:}

The child's psychological state has the clear effect of teaching him to read and write. The child needs psychological and emotional stability that precedes the actual start of teaching reading and writing. Scientific researches (Balousha, 2015: 21) (1) indicate that the child's personal, emotional and psychological problems are a major reason for the failure of the child to teach reading and writing. Here, the teacher must, before starting to teach and learn to read and write, recognize the students 'abilities and test their emotional state (Helles, 2015) : 44) (2) and seeks to achieve a safe classroom environment.

\section{Educational readiness:}

Before starting for teaching and learning to read and write, the child will have prepared an educational preparation that guarantees him success in teaching and learning to read and write by what he has acquired from: previous experiences, linguistic experiences, ability to distinguish audio, visual and speech, and the desire to read and write (Fahim 2002: 165) (3) These experiences are basic principles in teaching and learning to read and write, and the teacher's task is to build his activities in teaching and learning to read and write depending on the experience of his students and make it a cornerstone, and to take in the hands of those with little experience until they are able to start learning.

5. Child linguistic Dictionary:

There is a variation in the capacity of the child's linguistic dictionary, and the reason for this is the environment in which the child lives before the age of entering the school. The economic, cultural and social aspect of the family contributes to the capacity of the linguistic dictionary of the child, and the child who has the opportunity to speak, listen to stories and children's songs, visits and trips, contribute to The capacity of the linguistic dictionary (Helles, 2019, p. 23) (4), and it has a large number of words, which facilitates the processes of teaching and learning to read and write.

\section{Stages of reading development:}

Sholl (1983) (1) defined the stages of teaching literacy skills to pre-school children in four stages:

1- Preparation stage for introductory reading:

It extends from the moment of birth to the age of kindergarten, and includes what the child learns at home from the family and the media, where the child has an idea of letters, words and books, and here the 
International Journal of Childhood, Counselling, \& Special Education (CCSE), Volume1, Issue: 1, September: 2020, pp.39-57

child's vocabulary grows and his linguistic dictionary expands (Radwan, B,C, p. 8) (2) and the skills to be developed Children of this age have to prepare them to start teaching and learning to read, and to help them continue the process of teaching and learning to read successfully. A number of experts have identified aptitude skills, including: (Molfese et al 2006) (3).

- Hearing discrimination skill: it means the ability to distinguish verbal and auditory between one word and another, and one sound and another; So, the child acquires learning through hearing, and even reaches the degree of phonological analysis later.

- Visual discrimination skill: It is the ability to distinguish between two forms and between one word and another, and between one letter and another, and here learning is done by looking (seeing things) and the ability to distinguish between alphabets, words and phrases by contrasting them and comparing them.

- The skill of audiovisual discrimination: which represents the ability to recognize the names of things that students see in their environment, and to relate these written words to their pronunciation during phonemic analysis training, that is linking the graphemes to phonemes and developing the students outcome of words that they can read As a unit without breaking it down.

- Visual kinesthetic skill: the ability of students to move their eyes from right to left during reading by moving from one line to the next line smoothly.

\section{2- The stage of recognizing written symbols:}

It extends from the first to the second primary grade, where students learn the alphabet, and connect each letter with the corresponding parts of the spoken word, and the students develop the concept of reading and Olson define (Dillner \& Olson (1) 1982) Skills that written symbols as the skills that help the reader to pronounce letters, words or sentences, and to capture the meaning. This process consists of three aspects:

- Know the drawing of the letter, word or sentence.

- Spelling of a letter, word, or sentence.

- Know the meaning of the word or sentence.

\section{3- Spelling skill:}

It means the pupil's ability to pronounce written words and link words with their meaning. Olsen \& Dillener have classified their spelling skills into: 
International Journal of Childhood, Counselling, \& Special Education (CCSE), Volume1, Issue: 1, September: 2020, pp.39-57

- Phonetic analysis skill: (linking the written symbol with its pronunciation) that is the process of splitting the word into small written units, linking each written unit with its pronunciation, then merging the written units and spoken sounds to form syllables, pronouncing each syllable separately, and then merging the syllables together (Abu Harbeed, 2020- Master Thesis) (2).

- Structural analysis: it represents the student's ability to analyse the familiar word in the sense of stripping the compound word from the extra letters and syntactic signs, feminine and masculine signs, the sign of Deuteronomy and the plural, the nominative and accusative pronouns, the prepositions and conjunctions, the oath, the warning, the reception, assertiveness and negation, and using these parts to recognize the word The abstract and its meaning.

- Define the word in context: that is the ability to use information about the semantics (meanings of words) and the grammatical information in the context of the sentence, i.e. the syntax method and the position of the word in the sentence in order to identify its meaning, so semantic analysis and grammatical analysis cannot be separated from each other.

\section{4- Consolidation and Fluency Stage:}

Through this stage, what students learned in the previous stage is confirmed, and it includes the second and third grades by reading everything that is familiar and known, and here the students' ability to spell with repetition in the language they read emerges, and their ability to use context to increase fluency and reading speed.

\section{5- The Reading for Learning Stage:}

This stage includes the fourth to the eighth grade basic, and this stage is consistent with the traditional concept that says that the first three grades are the stage of teaching reading, and grades (4-5-6) are the beginning of the reading stage for learning and here it is imperative for the student to use his information and experiences During the process of reading, he reads in order to obtain facts and concepts, and how to make things (Helles, 2019) (1), and here students rely silent reading instead of aloud, to training on answering comprehension questions and rapid reading.

The researchers benefited from the previous theoretical framework in several matters as:

Preparing the scale elements, and the methodology used.

- Determine the objectives aimed at the current study and its relationship to previous studies.

- Identifying the statistical means to address the current study, as well as helping in analysing and interpreting 
International Journal of Childhood, Counselling, \& Special Education (CCSE), Volume1, Issue: 1, September: 2020, pp.39-57

the results, and deriving recommendations and proposals; To be more realistic and easier to apply.

\section{Study procedures:}

Study Approach:

The researchers adopted in their study the qualitative and quantitative descriptive approach, as the quantitative approach was adopted by calculating the marks that were collected for each student from the sample based on his score in the reading and writing readiness test and calculating the differences between males and females. As for the qualitative approach, it was done by identifying and discuss the readiness skills that should be possessed by first-grade basic students.

Study population and sample:

The study population consisted of all students of the first grade of basic school in the Dar Al-Arqam Islamic Model School in Gaza for the first semester of the academic year (2019 AD-2020 AD) and their number was: (203) male and female students, and the school was intentionally chosen. The study sample consisted of a sample of the study population, as its number reached: (64) male and female students, (31) male and female (33) female students, and $31.5 \%$ of the study population.

Study tools:
1. Aptitude test for teaching and learning to read and write:

- The initial image of the test:

The two researchers reviewed the educational literature related to the aptitude tests for teaching and learning to read and write, and then they prepared a test of readiness to learn and learn to read and write, where the test questions and vocabulary were built in light of the skills of readiness to teach and learn to read and write, and the test in its initial form was (30) A question divided into (5) skills: (visual discrimination, visual reminding, auditory discrimination, auditory reminding, and auditory interpretation).

-Determine the purpose of the test:

The test aims to identify the differences in the average scores for teaching and learning to read and write between males and females.

\section{-Test dimensions:}

The researchers determined the test dimensions, and (5) skills were chosen: (visual discrimination, visual recall, auditory discrimination, auditory recall, and auditory interpretation).

- Formulating the test vocabulary:

The test vocabulary was formulated in the style of a note card. The teacher places a score for each student in his card for all skill items. 
International Journal of Childhood, Counselling, \& Special Education (CCSE), Volume1, Issue: 1, September: 2020, pp.39-57

In this context (18) questions were formulated that represent the test in its initial form distributed on the preparedness skills specified in the test dimensions.

\section{-Test validation:}

To verify the validity of the test, it was presented to a group of (10) arbitrators in the field of curricula and teaching methods, and the Arabic language study to express an opinion on the appropriateness of the test vocabulary for the purpose of it and the accuracy of the linguistic and scientific formulation of the vocabulary, and the introduction of the modifications they deem appropriate. As the modifications of the referees resulted in some modifications in some vocabulary, and the scale remained in its final form consisting of (18) questions distributed on aptitude skills (visual discrimination, visual reminder, auditory discrimination, auditory reminding, auditory interpretation) and an exploratory study was also conducted. For the test with the aim of controlling it and determining its statistical characteristics, where the test was applied to a sample consisting of (30) male and female students of the first grade of the basic school of Dar Al-Arqam Islamic Model School, all of them from outside the original study sample, where the validity of the internal consistency of the test items was calculated after applying the test to the sample exploratory and all items of the test achieved significant correlations with the total score of the test at a significance level (0.05).

-Test stability:

The test stability factor was calculated after applying it to the exploratory sample using the halfsegmentation method using the Spearman Brown equation due to the equality of the two parts of the test, where the value of stability was (0.821), and the stability was also calculated using the Cronbach alpha equation, where the value of the test reliability was $(0.781)$, which is a coefficient High stability of this test, and indicates that the test can be used.

\section{Final form of the test:}

The number of the test questions in its final form was (18) questions, as the scoring for each question ranged between (1-5) scores for each correct answer, so the student's score was limited to between $[0,47]$ marks.

The following is the distribution of the number of items on the test domains: 
International Journal of Childhood, Counselling, \& Special Education (CCSE), Volume1, Issue: 1 , September: 2020, pp.39-57

Table 1. Distribution of the test items on the domains

\begin{tabular}{lcccccc}
\hline & $\begin{array}{c}\text { Visual } \\
\text { discrimination }\end{array}$ & $\begin{array}{c}\text { Visual } \\
\text { reminder }\end{array}$ & $\begin{array}{c}\text { Auditory } \\
\text { discrimination }\end{array}$ & $\begin{array}{c}\text { Audio } \\
\text { reminder }\end{array}$ & $\begin{array}{c}\text { Auditory } \\
\text { interpretation }\end{array}$ & $\begin{array}{c}\text { Total } \\
\text { marks }\end{array}$ \\
$\begin{array}{l}\text { Number of } \\
\text { paragraphs }\end{array}$ & 8 & 2 & 3 & 4 & 1 & 18 \\
\hline
\end{tabular}

\section{Study steps}

The researchers performed the following procedures:

1. Access to previous studies related to the research topic.

2. Determine the skills necessary for teaching and learning to read and write among first-grade students.

3. Preparing the study tool and ensuring its validity and reliability.

4. The application of the study tool in the first two weeks of the beginning of the first semester of the year (2019-2020 AD), after all the procedures necessary for the application have been set, and then the grades have been monitored, data entered and processed statistically using the (SPSS) program.

\section{Study results}

Results related to the first question and its discussion:
The first of the study questions states: "What skills should a firstgrade pupil possess upon entering school in preparation for teaching and learning to read and write?"

To answer this question, the two researchers reviewed the educational literature and previous studies that dealt with the skills of readiness to teach and learn to read and write, and then they determined the skills that the first grade pupil should possess upon entering school in preparation for teaching and learning to read and write, and then presented them to a group of arbitrators to make sure Their validity and comprehensiveness, and after adding the amendments referred to by the arbitrators, the researchers reached a set of skills, and Table (1) shows the skills that a first-grade pupil should possess upon entering school in preparation for teaching and learning to read and write.

Table 2. The skills that a first grade pupil should possess upon entering school in preparation for learning to read and write.

\begin{tabular}{l} 
Skills \\
$\begin{array}{l}\text { First: } \quad \text { Distinguish the different shape. } \\
\text { discrimination }\end{array}$ \\
$\begin{array}{l}\text { - Paints the same shape. } \\
\text { - Plaws an a point inside a square and draws a circle around the stick. } \\
\text { - Make a point inside the circle and a circle around the square. }\end{array}$ \\
\hline
\end{tabular}


International Journal of Childhood, Counselling, \& Special Education (CCSE), Volume1, Issue: 1 , September: 2020, pp.39-57

\begin{tabular}{|c|c|}
\hline $\begin{array}{l}\text { Second: visual } \\
\text { reminder }\end{array}$ & $\begin{array}{l}\text { • He paints the shape he likes. } \\
\bullet \text { Hedges like couples. } \\
\text { Marks the word that matches the known word. } \\
\text { - mention the name of the missing image. } \\
\text { - Complete the minus fee. }\end{array}$ \\
\hline $\begin{array}{l}\text { Third: auditory } \\
\text { discrimination }\end{array}$ & $\begin{array}{l}\text { • Mimics sounds from the environment. } \\
\text { - Acoustically identifies identical words. } \\
\text { - Distinguishes the picture whose name begins with the same letter required. }\end{array}$ \\
\hline $\begin{array}{l}\text { Fourth: Auditory } \\
\text { reminder }\end{array}$ & $\begin{array}{l}\text { After the teacher, the student speaks a series of words that he hears: } \\
\text { - A series of two words } \\
\text { - A series of three words. } \\
\text { - A series of four words. } \\
\text { - The student utters the numbers after the teacher in the same order. }\end{array}$ \\
\hline $\begin{array}{l}\text { Fifth: Auditory } \\
\text { interpretation }\end{array}$ & - Executes the instructions given to him by the teacher. \\
\hline
\end{tabular}

\section{Results related to the second question:}

The second question states: "Are there statistically significant differences at a significant level $(\alpha \leq$ $0.05)$ between the average scores of readiness to teach and learn to read and write between males and females?"

To answer this question, the researchers tested the following hypothesis: "There are no statistically significant differences at a significant level $(\alpha \leq 0.05)$ between the average readiness scores of first-grade students, the basis for teaching and learning to read and write, due to the gender variable."

To test the hypothesis related to the second question, the T-test was used for two independent samples, "Independent Samples $t$ test" to compare the average degrees of readiness for teaching and learning to read and write between males and females, and the results were as shown in Table (3).

Table 3. Results of "Independent Samples t test" to compare the average scores of readiness for teaching and learning to read and write between males and females.

\begin{tabular}{|c|c|c|c|c|c|c|c|}
\hline Skill & group & No & Average & $\begin{array}{l}\text { standard } \\
\text { deviation }\end{array}$ & $\begin{array}{l}\mathrm{T} \\
\text { value }\end{array}$ & sig & $\begin{array}{l}\text { Statistical } \\
\text { significanc } \\
\mathrm{e}\end{array}$ \\
\hline \multirow{2}{*}{$\begin{array}{l}\text { visual } \\
\text { discrimination }\end{array}$} & Male & 31 & 8.290 & 1.0390 & \multirow{2}{*}{1.588} & \multirow{2}{*}{0.117} & \multirow{2}{*}{$\begin{array}{l}\text { no } \\
\text { statistically } \\
\text { significant }\end{array}$} \\
\hline & female & 33 & 8.379 & 1.2932 & & & \\
\hline \multirow{2}{*}{ visual reminder } & Male & 31 & 13.58 & 1.911 & \multirow[b]{2}{*}{0.300} & \multirow[b]{2}{*}{0.765} & no \\
\hline & female & 33 & 14.48 & 1.064 & & & $\begin{array}{l}\text { statistically } \\
\text { significant }\end{array}$ \\
\hline \multirow{2}{*}{$\begin{array}{l}\text { auditory } \\
\text { discrimination }\end{array}$} & Male & 31 & 3.532 & 1.0641 & \multirow[b]{2}{*}{2.357} & \multirow[b]{2}{*}{0.022} & statistically \\
\hline & female & 33 & 4.091 & 0.8879 & & & $\begin{array}{l}\text { significant } \\
\text { at } 0.05\end{array}$ \\
\hline
\end{tabular}


International Journal of Childhood, Counselling, \& Special Education (CCSE), Volume1, Issue: 1 , September: 2020, pp.39-57

\begin{tabular}{llllllll}
\hline Auditory reminder & Male & 31 & 2.81 & 0.402 & & & \\
& female & 33 & 2.88 & 0.331 & 2.286 & 0.026 & $\begin{array}{l}\text { statistically } \\
\text { significant } \\
\text { at } 0.05\end{array}$ \\
auditory & Male & 31 & 44.048 & 4.7581 & & & $\begin{array}{l}\text { no } \\
\text { interpretation }\end{array}$ \\
female & 33 & 46.258 & 2.9078 & 0.788 & 0.434 & $\begin{array}{l}\text { statistically } \\
\text { significant }\end{array}$ \\
\hline
\end{tabular}

* The value of $(t)$ at the degree of freedom $(62)$ and the level of significance $(0.05)=1.999$. The value of $(t)$ at the degree of freedom (62) and the level of significance $(0.01)=2.657$.

\section{The table shows the following:}

First: regards to the total score of the test of readiness for teaching and learning to read and write:

That the value of $t$ calculated for the total score of the test of readiness for teaching and learning to read and write is equal to (2.257) and it is greater than the tabular value of $t$ at the level of significance (0.05) and the degree of freedom (62), which equals (1.999), and accordingly the null hypothesis was rejected, meaning that there are significant differences astatistic at the level of significance $(\alpha=0.05)$ in the average degrees of readiness for teaching and learning to read and write between males and females in favor of females as the arithmetic mean of females is equal to (46.258) which is greater than the arithmetic mean of males, which equals (44.048).

Second: regards to the skill of visual discrimination:

That the value of $t$ calculated for the skill of visual discrimination is equal to (1.588) and it is less than the tabular value of $t$ at the level of significance (0.05) and the degree of freedom (62) which is equal to (1.999), that is, there are no statistically significant differences at the level of significance $(a=0.05)$ in Average scores for visual discrimination in readiness for teaching and learning to read and write between males and females.

Third: regards to the skill of visual reminder:

That the value of $t$ calculated for the skill of visual reminder is equal to $(0.300)$ and it is less than the tabular value of $t$ at the level of significance (0.05) and the degree of freedom (62) which is equal to (1.999), meaning that there are no statistically significant differences at the level of significance $(a=0.05)$ in Average score for visual recall skill in readiness for teaching and learning to read and write among males and females. The researchers confirm that the instructions and directions for students how to distract their eyes from the visual stimuli present in the pictures contributed to acquiring the skill of reading recognition. 
International Journal of Childhood, Counselling, \& Special Education (CCSE), Volume1, Issue: 1, September: 2020, pp.39-57

Fourth: regards to the skill of auditory discrimination:

That the value of $t$ calculated for the skill of auditory discrimination is equal to (2.286) and it is greater than the tabular value of $t$ at the level of significance $(0.05)$ and the degree of freedom (62), which equals (1.999) and therefore the null hypothesis was rejected, that is, there are statistically significant differences at the level of significance $(A=0.05)$ in the average degrees of auditory discrimination skill in readiness for teaching and learning to read and write between males and females in favor of females as the arithmetic mean of females equals (14.48) which is greater than the arithmetic mean of males, which equals (13.58).

Fifth: regards to the skill of auditory reminder:

That the value of $t$ calculated for the auditory reminder skill is equal to 2.357 , which is greater than the tabular value of $t$ at the level of significance (0.05) and the degree of freedom (62), which equals (1.999). Therefore, the null hypothesis was rejected, meaning that there are statistically significant differences at the level of significance $(\mathrm{a}=0.05)$. in the average scores of the auditory reminder skill in preparing to teach reading and writing between males and females in favor of females as the arithmetic mean of females is equal to (4.091), which is greater than the arithmetic mean of males, which equals (3.532).

Sixth: regards to the skill of auditory interpretation:

That the value of $t$ calculated for the skill of auditory interpretation is equal to (0.788) and it is less than the tabular value of $t$ at the level of significance of 0.05 and the degree of freedom (62) which is equal to (1.999), that is, there are no statistically significant differences at the level of significance $(a=0.05)$ in the average Degrees of aural interpretation skill in readiness for teaching and learning to read and write among males and females.

\section{Calculate the effect size:}

To calculate the size of the effect, the ETA square ( $\eta 2)$ was used according to

the following equation (Afana, 2000, p. 34):

$$
\eta^{2}=\frac{t^{2}}{t^{2}+d f}
$$

- $(\eta 2)$ : The proportion of the total variance in the dependent variable that is due to the independent variable.

- (T2): the square of the value of T.

- $(\mathrm{df})$ : degree of freedom.

The following table shows the levels of impact according to the ETA Square ( $\eta 2)$ (Afana, 2016, p.52) (1) 
International Journal of Childhood, Counselling, \& Special Education (CCSE), Volume1, Issue: 1, September: 2020, pp.39-57

Table 4. Shows the levels of effect size.

\begin{tabular}{cccc}
\hline Effect degree & Small & Medium & large \\
\hline the ETA square $(\eta 2)$ & 0.01 & 0.06 & 0.14 \\
\hline
\end{tabular}

Table 5. Shows the value of the ETA square $(\eta 2)$.

\begin{tabular}{lccl}
\hline Skill & T calculated value & $\begin{array}{c}\text { ETA square } \\
(\boldsymbol{\eta} 2):\end{array}$ & Effect size \\
\hline Auditory discrimination & 2.357 & 0.08 & Medium \\
Audio reminder & 2.286 & 0.08 & Medium \\
Total score for the readiness test for & 2.257 & 0.08 & Medium \\
learning to read and write & & & \\
\hline
\end{tabular}

Table $(4,5)$ define that the values of the ETA square coefficient $(\eta 2)$ are average in the total score of the test of readiness for teaching and learning to read and write and in the two skills of auditory discrimination and auditory recall, and this means that the size of the differences between males and females in the readiness for teaching and learning to read and write and in the skills of auditory discrimination and reminder The auditory is moderate, and the two researchers confirm that first-grade basic students find it difficult to pronounce words that start with similar letters in pronunciation. This is in agreement with the study of both: Al-Jarf (1994) (1), Tunmr and Tunmr Herriman (1988) (2), and Williams (1986) (3). The researchers refer to the following:

The training that kindergarten children receive in auditory discrimination exercises are few and need to be selected, and that the main reason for individual differences between students was the ability to perceive the classification of similar sounds, which is one of the components of readiness to teach reading and writing, which requires first-grade teachers to take care of preparing additional exercises to enhance This ability.

\section{Recommendations and suggestions:}

Based on the results
demonstrated by the study,
researchers recommend the
following:

- Urging the authorities supervising kindergartens to hold training courses for Riyadh teachers dealing with the skills necessary for reading and writing readiness (audio and visual discrimination)

- That the preparatory week exercises for the first grade student to enter the school include more audio and visual discrimination exercises 
International Journal of Childhood, Counselling, \& Special Education (CCSE), Volume1, Issue: 1, September: 2020, pp.39-57

- Evaluating our beautiful language books developed for the elementary grades in light of national standards for education

- Conducting a study on the effect of pictures in the books of Our Beautiful Language for the first grade, the basis for acquiring the skill of reading.

\section{References}

Abdel-Rahman, Saad and Ahmed, Faiqa (2002) Willingness to learn, write, develop and measure in kindergarten. Cairo: Al Falah Library.

Abdel-Rahman, Saad and Zaki, Iman (2002). Readiness to learn to read, its development and measurement in the kindergarten stage. Cairo Al Falah Library.

Abu Harbeed, Huda (2020) The extent to which our beautiful language books include the initial classes of phonemic awareness and a proposed visualization to enrich them. A magister message that is not published. Islamic University of Gaza.

Afaneh, Izzo (2016) Measurements of effect size and inferential statistics in educational and psychological research, Gaza: Mansour Library.

Al-Alouni, Aziza et al. (1432) The effectiveness of an electronic program in developing some readiness skills for reading and writing among pre-school children. The second scientific conference for students of higher education - the Kingdom of Saudi Arabia, held on $23-26 / 4 / 1432$.

Al-Jarf, Rima Saeed (1994) Analysis of errors in recognizing written symbols among first, second, and third primary school students in the Kingdom of Saudi Arabia. Unpublished Master Thesis - King Fahd National Library.

Al-Jumaili, Raghad (2004) The difficulties of teaching literacy for beginners from the point of view of teachers and supervisors. Unpublished MA Thesis, College of Education, Ibn Rushd - University of Baghdad.

Al-Mutlak, Kanaan (2004) Language experiences in kindergartens, Damascus University Press. Syrian.

Al-Nashif, Huda (2005) Designing educational programs for pre-school children. Modern Book House, Egypt.

Al-Tahan, Taher Ahmad (2003) Preparedness for Reading in Early Childhood, Amman: Arab Thought House.

Al-Tahan, Tahira Ahmed (1994) Readiness to read among children in Riyadh (diagnosis and development), an unpublished master's thesis, Faculty of Education - Mansoura University, Egypt. 
International Journal of Childhood, Counselling, \& Special Education (CCSE), Volume1, Issue: 1 , September: 2020, pp.39-57

Balousha, Salwa (2015) The Effectiveness of Employing Al-Qaeda Al Nourania in Treating Reading Dysfunction among Third-Grade Students, Unpublished Master Thesis, Islamic University of Gaza.

Barghout, Rehab (2002) A proposed program of activities to develop some readiness for reading and writing skills for children with learning difficulties in kindergarten. Unpublished $\mathrm{PhD}$ thesis, Ain Shams University, Egypt.

Chall J (1983) Stages of Reading Development MC Graw-Hill Book Company.

shogir, Muhammad and Helles, Daoud (2010) Effective Teaching Skills. Afaq Library, Gaza Palestine.

Elsea, Beck (2001) Inerasing student, $s$ reading readins skills through the use of abalanced literacy program Master degree thesi saint Xavier university. ED 454505.

Fahim, Mustafa (2002) Preparing the child for reading in kindergarten. Cairo: The Arab Book House Library, Egypt.

Farag, Abdel-Qader and others (BT) Dictionary of Psychology - Beirut: Dar Al-Nahda Al-Arabiya

Helles, Daoud (2015) Modern trends in methods of teaching the Arabic languae, Gaza: Al-Jazeera Library.
Helles, Daoud (2019) A contemporary vision in teaching reading and writing skills to elementary grades, Gaza: Al-Rehab Library

Khairallah Syed, Mamdouh AlKinani (1996) The psychology of learning between theory and practice. Renaissance House, Egypt.

Molfese, V., Modglin, A., Bewick, J., Neamone, J., Berg, S., Berg, C., \& Molnar, A. 2006. Letter knowledge, phonological processing, and print knowledge: Skill development in non-reading preschool children. Journal of learning diseases, 39 (4), p: 296-305. Doi: $10.1111 /$ j. 15405826.2008.00269.x.

Nejm, Abdullah (2006) The reasons for the weakness of primary school students in reading from the viewpoint of Arabic language teachers in the elementary stage in Iraq - Bisan University - College of Education.

Olsn, A. \& Dillner, M (1982) learning to teach reding in the elementary school. (2nd ed) Macmillan publishing co. INC

Radwan, Muhammad (BT) The child prepares for reading. Knowledge House, Egypt.

Snow, c, burns, m, \& Griffin, P 1998 preventing reading difficulties in Young children Washington, DC: National Academy. 
International Journal of Childhood, Counselling, \& Special Education (CCSE), Volume1, Issue: 1, September: 2020, pp.39-57

Taha, Faraj and others (BT) Dictionary of Psychology and Psychoanalysis. Beirut: Dar AlNahda.

Tunmer, E. Herrimam, M, \& Nesdale, A. (1988). Metalinguistic abilities and beginning reading research Quarteriy 23 134-158.

Williams, J. (1986) the role of phonemic analysis in reading INJ Torgesen and B.

Zaki Muhammad (2002) Readiness to learn to read, to develop and measure it in kindergarten, Al Falah Library, Kuwait. 